\title{
To beat acute kidney injury, you need to keep your eye on the goal
}

\author{
James A. DiNardo, MD, FAAP
}

From the Harvard Medical School, Division of Cardiac Anesthesia, Boston Children's Hospital, Boston, Mass. Disclosures: Author has nothing to disclose with regard to commercial support.

Received for publication Sept 16, 2016; accepted for publication Sept 16, 2016; available ahead of print Oct 14, 2016.

Address for reprints: James A. DiNardo, MD, FAAP, Department of Anesthesiology, Boston Children's Hospital, 300 Longwood Ave, Boston, MA 02115 (E-mail: james.dinardo@ childrens.harvard.edu).

J Thorac Cardiovasc Surg 2017;153:126-7

$0022-5223 / \$ 36.00$

Copyright (c) 2016 by The American Association for Thoracic Surgery

http://dx.doi.org/10.1016/j.jtcvs.2016.09.032

In this issue of the Journal, Magruder and colleagues ${ }^{1}$ present the results of a goal-directed perfusion initiative designed to reduce acute kidney injury (AKI) associated with cardiac surgery in adults. Goal-directed therapies have been described since the 1980 s. $^{2}$ The concept gained attention in 2001 with the publication of results demonstrating improved outcome in severe sepsis and septic shock when early goal-directed therapy was initiated. ${ }^{3}$ Ironically, recent attempts to replicate the success of this early goaldirected therapy protocol in severe sepsis have failed to demonstrate improved outcomes compared with conventional therapy. ${ }^{4}$ Proponents of goal-directed therapy would argue, in this case, that conventional therapy has evolved to include the original, important goal-directed interventions, and thus the 2 have converged. In the case of severe sepsis, this is early aggressive fluid administration. Successful goal-directed therapy ultimately should become conventional therapy.

For goal-directed therapy to be effective, tangible bias must be avoided., "Favoring less important but immediately measurable variables, such as mean arterial blood pressure (MAP), over more important but less measurable variables, such as tissue oxygen delivery $\left(\mathrm{DO}_{2}\right)$, is the result of 'tangible bias,' our tendency to favor what we can see and understand over what we cannot." 6 Furthermore, there must a solid, evidence-based physiologic link between the goal-directed therapies and the desired outcome. Factors implicated in the genesis of AKI-associated cardiac surgery have been extensively reviewed by Thiele and colleagues. ${ }^{7}$

For the most part, Magruder and colleagues ${ }^{1}$ have done an admirable job of assembling an evidence-based, goaldirected perfusion protocol. Minimizing cardiopulmonary bypass (CPB) circuit volume should be common practice given that both anemia (dilutional or otherwise) and transfusion to treat anemia during CPB consistently have been identified as a risk factors for AKI. ${ }^{8-10}$ The evidence presented to support threshold oxygen delivery values during CPB to reduce AKI is solid. ${ }^{11-13}$ Evidence cited to justify the use of zero balanced ultrafiltration (ZBUF) to

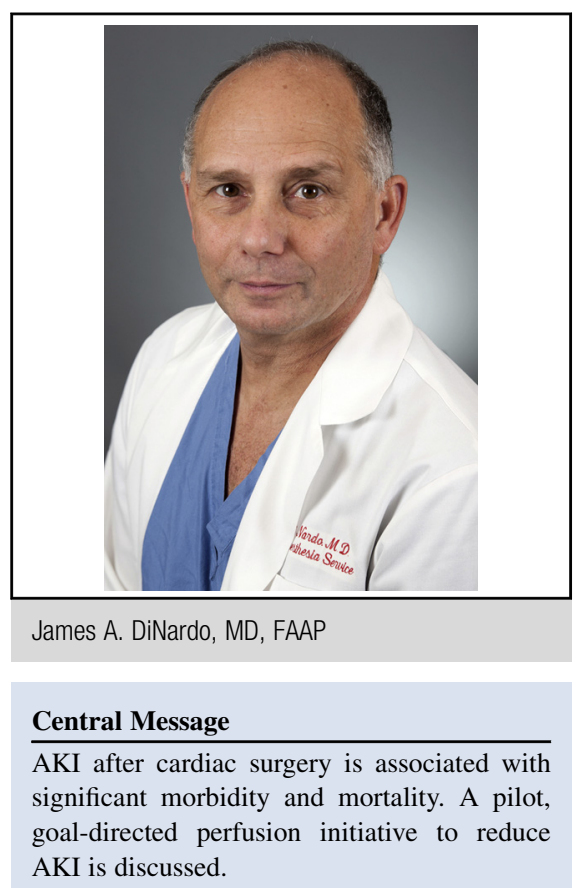

See Article page 118

reduce the risk of AKI is less convincing. Although patients with impaired renal function (estimated glomerular filtration rate $<60 \mathrm{~mL} / \mathrm{min}$ adjusted for $1.73 \mathrm{~m}^{2}$ of body surface area) randomized to ZBUF or no ZBUF during CPB demonstrated lower estimated glomerular filtration values, urinary neutrophil gelatinaseassociated lipocalin/urinary creatinine ratio, creatinine values, and urea values on admission to the intensive care unit in the ZBUF group, none of these improvements were sustained at 24 hours or more. ${ }^{14}$ It is plausible that avoidance of overzealous continuous ultrafiltration is more important than the use of ZBUF. ${ }^{15}$ It makes intuitive sense to limit the rapidity of rewarming; however, the evidence presented is inferential, referring to the relationship of rewarming rate to neuronal damage. Avoidance of phenylephrine to support mean arterial pressure on CPB makes sense given that increases in CPB flow rate will increase oxygen delivery and that animal data suggest phenylephrine reduces renal blood flow. ${ }^{7}$ Finally, mannitol use to reduce AKI is of unproven value and was avoided.

Where does this leave us? This study is an excellent first step in what hopefully will be the evolution of a welldevised, goal-directed protocol into conventional care. 


\section{References}

1. Magruder JT, Crawford TC. A pilot goal-directed perfusion initiative is associated with less acute kidney injury after cardiac surgery. $J$ Thorac Cardiovasc Surg. 2017; 153:118-25.

2. Gallagher TJ, Civetta JM. Goal-directed therapy of acute respiratory failure. Anesth Analg. 1980;59:831-4.

3. Rivers E, Nguyen B, Havstad S, Ressler J, Muzzin A, Knoblich B, et al; Early Goal-Directed Therapy Collaborative Group. Early goal-directed therapy in the treatment of severe sepsis and septic shock. N Engl J Med. 2001;345: 1368-77.

4. Schindler E, Photiadis J, Sinzobahamvya N, Döres A, Asfour B, Hraska V. Tranexamic acid: an alternative to aprotinin as antifibrinolytic therapy in pediatric congenital heart surgery. Eur J Cardiothorac Surg. 2011;39:495-9.

5. Magder S. Phenylephrine and tangible bias. Anesth Analg. 2011;113:211-3.

6. Thiele RH, Nemergut EC, Lynch C. The physiologic implications of isolated alpha(1) adrenergic stimulation. Anesth Analg. 2011;113:284-96.

7. Thiele RH, Isbell JM, Rosner MH. AKI associated with cardiac surgery. Clin J Am Soc Nephrol. 2015;10:500-14.

8. Swaminathan M, Phillips-Bute BG, Conlon PJ, Smith PK, Newman MF, Stafford-Smith M. The association of lowest hematocrit during cardiopulmonary bypass with acute renal injury after coronary artery bypass surgery. Ann Thorac Surg. 2003;76:784-92.

9. Karkouti K, Wijeysundera DN, Yau TM, McCluskey SA, Chan CT, Wong P-Y, et al. Influence of erythrocyte transfusion on the risk of acute kidney injury after

cardiac surgery differs in anemic and nonanemic patients. Anesthesiology. 2011 115:523-30.

10. Karkouti K, Beattie WS, Wijeysundera DN, Rao V, Chan C, Dattilo KM, et al Hemodilution during cardiopulmonary bypass is an independent risk factor for acute renal failure in adult cardiac surgery. J Thorac Cardiovasc Surg. 2005; 129:391-400.

11. Magruder JT, Dungan SP, Grimm JC, Harness HL, Wierschke C, Castillejo S, et al. Nadir oxygen delivery on bypass and hypotension increase acute kidney injury risk after cardiac operations. Ann Thorac Surg. 2015;100:1697-703.

12. De Somer F, Mulholland JW, Bryan MR, Aloisio T, Van Nooten GJ, Ranucci M $\mathrm{O} 2$ delivery and $\mathrm{CO} 2$ production during cardiopulmonary bypass as determinants of acute kidney injury: time for a goal-directed perfusion management? Cri Care. 2011;15:R192.

13. Ranucci M, Romitti F, Isgrò G, Cotza M, Brozzi S, Boncilli A, et al. Oxygen delivery during cardiopulmonary bypass and acute renal failure after coronary operations. Ann Thorac Surg. 2005;80:2213-20.

14. Matata BM, Scawn N, Morgan M, Shirley S, Kemp I, Richards S, et al. A singlecenter randomized trial of intraoperative zero-balanced ultrafiltration during cardiopulmonary bypass for patients with impaired kidney function undergoing cardiac surgery. J Cardiothorac Vasc Anesth. 2015;29:1236-47.

15. Paugh TA, Dickinson TA, Martin JR, Hanson EC, Fuller J, Heung M, et al; Michigan Society of Thoracic and Cardiovascular Surgeons, Perfusion Measures and Outcomes PERForm Registry. Impact of ultrafiltration on kidney injury after cardiac surgery: the Michigan experience. Ann Thorac Surg. 2015;100:1683-8. 